\title{
A motivação moral e o suicídio na ética de Schopenhauer: o caso do auto-sacrifício de uma enfermeira italiana ao contrair a covid-19
}

\author{
The moral motivation in a suicide: the self-sacrifice of an italian nurse when \\ contracting the covid-19 in Schopenhauer's ethics
}

\begin{abstract}
Alex Andrade*
Resumo: Este trabalho tem como objetivo fazer uma análise da motivação da enfermeira italiana que, após o diagnóstico positivo para o novo coronavírus SARS-CoV-2, cometeu suicídio. Desde que esta doença se tornou uma pandemia, distintas reações das pessoas têm sido observadas nas várias sociedades pelo mundo. Para efeito de referencial teóricofilosófico, debruçaremos sobre a ética schopenhaueriana a fim de refletir sobre o suicídio de Daniela Trezzi. Inicialmente, traremos, em linhas gerais, o contexto e o fato ocorrido. Em seguida, abordaremos as justificativas do julgamento condenatório do filósofo alemão a respeito do suicídio. No segundo momento deste trabalho, confrontaremos o suicídio da italiana dentro da filosofia schopenhaueriana e refletiremos a respeito das motivações morais. Seria este suicídio motivado, não por conta dos males que a doença lhe trarią, ou seja, motivado não em virtude do sofrimento pessoal, mas sim por compaixão ao imaginar o mal que ela causaria aos outros?

Palavras-chave: Coronavírus; Schopenhauer; Ética; Suicídio; Auto-sacrifício
\end{abstract}

Abstract: This study is object to do an analysis of an italian nurse motivation to commit suicide, after being diagnosed with the new Corona Virus SARS-CoV-2. Ever since this sickness became pandemic, people around the world have been having different reactions in their different societies. As a theoretical-philosophical reference, we shall lean over Schopenhauer's ethics in order to reflect on Daniela Trezzi suicide. Firstly, we will bring, in general lines, the context and the occurred fact. In a second moment, we will approach the justifications of the condemning judgement in respects to suicide according to the German philosopher. In this second moment, we will confront the nurse suicide in respect to Schopenhauer philosophy, and ponder over the moral motivations. Would this suicide be motivated not by the afflictions that the disease would bring her, that is, motivated not in reason of personal suffering, but by compassion, in imagining the harm that she would cause others.

Keywords Coronavirus; Schopenhauer; Ethics; Suicide; Self-Sacrifice

\section{A pandemia da covid-19 e caos instaurado na Itália}

O mundo foi abalado com a descoberta de um novo agente coronavírus intitulado SARS-CoV-2 no final do mês de dezembro de 2019 em Wuhan, uma cidade localizada na China. O coronavírus é uma família de vírus que causam doenças respiratórias, o que parece ser bem comum visto que já lidamos e continuamos a lidar diariamente com outros coronavírus. Porém, de modo desenfreado devido ao seu altíssimo poder de contágio, a cidade de 11 milhões de habitantes começou a sentir seus efeitos fatais e logo alcançou o colapso do sistema de saúde devido à covid-19, doença causada pelo SARS-CoV2. Logo a doença ultrapassou os limites chineses e passou a surgir em diversos outros países. Foi então que, no dia 11 de março, a Organização Mundial de Saúde (OMS) elevou a covid-19 ao status de pandemia.

Desde que se tornou uma pandemia, os governos mundiais vêm se mobilizando para combater esta doença. Como medida de contenção da propagação do vírus, diversas cidades 
pelo mundo têm adotado o regime de isolamento social, isto é, as pessoas deveriam permanecer em suas casas sem contato com as outras para que não houvesse aglomerações justamente para frear o número de infectados e de óbitos. É esta a recomendação que a OMS tem dado. Alguns governos, de modo responsável, agiram rápido e com o rigor necessário para combater e conter a doença, mas outros governos agiram de modo negligente e o resultado tem sido devastador.

Os números assustam. A quantidade de infectados e de mortos só aumenta pelo mundo a cada dia. O medo se assolou em cada lar de família, ou ao menos já deveria ter causado pelo menos uma preocupação. Na Itália, a situação é desoladora. Desde os dois primeiros casos confirmados no dia 31 de janeiro, o país entrou numa crise sanitária sem precedentes. Os números de casos, dois meses depois, já ultrapassam os 150 mil e os casos fatais somam mais de 20 mil casos. Essa tragédia se deu por conta da demora, por parte do governo italiano, de tomar medidas combativas. O próprio prefeito de Milão, hoje arrependido diante do desastre, debochou da covid-19 e apoiou uma campanha para a cidade não parar. É no meio desse caos que iremos tratar especificamente do caso da enfermeira Daniela Trezzi. Ela trabalhava na unidade de terapia intensiva do Hospital San Geraldo, na região da Lombardia que, segundo o governo Italiano, foi a região mais atingida pelo novo coronavírus. Até o final do mês de março, foram 43.208 casos e atualmente conta com quase 89 mil casos dos 233.197 no país. Sendo assim, o epicentro da Covid-19 na Itália.

Segundo a Federação Nacional de Enfermeiros da Itália (FNOPI), Daniela e seus colegas, trabalhavam sob forte estresse. Ela trabalhava na linha de frente em Monza, cidade próxima a Milão. No dia 10 de março, a enfermeira recebeu a notícia de que havia sido contaminada e teve que se afastar do trabalho, ir para a quarentena se tratar. No dia 24 de março, Daniela suicidou-se. O diretor do hospital de San Geraldo confirmou que ela havia cometido suicídio. Em nota, a federação afirmou que, segundos seus colegas, ela estava sob efeito de muito estresse e com muito medo de contaminar outras pessoas. A pergunta que fazemos é: este "medo" não poderia ser o sentimento da compaixão? Esse medo era da possibilidade de causar sofrimento a outros? Para podermos adentrar nesta investigação dentro da filosofia schopenhaueriana, primeiramente é necessário esclarecer algumas questões referentes à afirmação e a negação da Vontade, ${ }^{1}$ os três tipos de motivações das ações e o único motivador moral segundo o alemão e, por fim, mostrar o porquê de Schopenhauer condenar o suicídio por considerar se tratar de um ato próprio da afirmação da Vontade, ou seja, uma ação antimoral.

\section{Schopenhauer e o suicídio}

A natureza das ações humanas, segundo Schopenhauer, tem uma relação direta com a sua metafísica da Vontade. Ela é um ímpeto cego que rege tudo e a todos no mundo que tem a sua máxima objetivação em nossos corpos. "Eis por que, em vez de afirmação da Vontade, podemos também dizer afirmação do corpo” (W I, p.379). Este princípio não possui qualquer fundamento racional. A Vontade é una, mas una não como oposição ao que é plural, mas porque está fora do tempo, espaço e dos princípios causais. É o princípio

\footnotetext{
${ }^{1}$ Aqui seguirei usando, como faz Jair Barboza na segunda edição da sua tradução, Vontade com a inicial maiúscula como coisa em-si do mundo "Wille zum Leben"("Vontade de vida”) para diferenciar das vontades, em minúsculo, como o querer, do alemão Woller, no sentido empírico. Importante salientar que a Vontade é uma coisa só. Ainda que tenha um sentido metafísico de unicidade e um outro como multiplicidade das diversas representações encontradas no mundo. Além disso, na língua alemã todo substantivo é grafado com a inicial maiúscula, portanto a vontade, do alemão Wille, inicia-se com uma consoante no maiúsculo.
} 
metafísico presente em todas as coisas. Os objetos que podemos conhecer através do tempo, espaço e da casualidade são representações e elas estão no mundo. "O mundo é representação" (W I, p. 4). Mas o mundo como representação é uma mera cópia da sua verdadeira essência que é a Vontade. Todo conhecimento obtido através da razão e dos sentidos é um conhecimento ilusório, pois "é apenas a imagem copiada da sua essência" (W I, p. 175). Então é dentro desse contexto em que o homem vive a sua falsa liberdade afirmando cada vez mais seus desejos do corpo afim de satisfazer a insaciável Vontade.

Para o filósofo, nós somos naturalmente egoístas. É simplesmente compreensível e comum que as pessoas escolham e ajam em benefício próprio, visto que afirmar as vontades do corpo é afirmar a própria Vontade. Além disso, a afirmação da Vontade ocorre constantemente por conta de um estado de eterna insatisfação em todas as representações. Isso gera um conflito entre elas por espaço, por matéria e tempo. Essa batalha é mais facilmente visível no reino animal onde ora se é predador, ora se é presa. Por isso, a Vontade é o mesmo do que dizer Vontade de vida, visto que ela busca a manutenção da vida em suas finitas representações dentro do mundo. Essa manutenção se dá justamente afirmando a Vontade através do corpo que alcança seu grau máximo no gênero humano devido a sua capacidade racional. Para acentuar o egoísmo, Schopenhauer diz que o homem sente uma eterna carência dentro de si. Se estamos com sede, bebemos água; mas logo estaremos com sede novamente e, outra vez, teremos que beber. É uma insatisfação sem fim.

Através da conexão causal das coisas, a maioria das cobiças tem de permanecer impreenchível e a vontade é mais frequentemente contrariada que satisfeita; em consequência, querer intenso e veemente sempre traz consigo sofrimento intenso e veemente. Pois todo sofrimento nada é senão querer insatisfeito e contrariado (W I, p.422).

O resultado dessa insatisfação sem fim, além de dar origem ao sofrimento do homem, alimenta a voracidade do egoísmo humano. Para além das ações naturais egoísticas, mas também antimorais, são as ações maldosas. "A maldade é a alegria diabólica. De acordo com a ética schopenhaueriana, as pessoas só possuem três tipos de motivação para os seus atos: o egoísmo, a maldade e a compaixão. A primeira raiz mais animal, a segunda mais diabólica" (E II, p. 127). O filósofo nos diz que sua origem está nas constantes amarguras e sofrimentos que a vida nos proporciona. Com isso, após guardar dentro de si todos esses sentimentos penosos, ele sente que é preciso descarregar nas outras pessoas. Nesse momento, o maldoso se torna cruel.

Apesar de, assim como o egoísmo, não ser uma atitude considerada moral, as ações cruéis não possuem interesse no agente como ocorre com o egoísta. Na crueldade, o ato do agente é completamente desinteressado. O objetivo dos atos cruéis é somente causar sofrimento ao outro, ainda que isto cause algum tipo de mal ao agente. A explicação para isso é porque a sua satisfação está em causar sofrimentos alheios. O fim da ação cruel está no outro, não no próprio agente. Por outro lado, o homem egoísta usa o outro como meio para a sua satisfação íntima, a satisfação íntima do homem cruel está somente no sofrimento alheio. O primeiro tem a si mesmo como o fim das suas ações; o segundo tem o outro como fim das suas ações.

Desse tormento interior que lhes é inteiramente imediato e essencial procede, por fim, até mesmo a alegria no sofrimento alheio, que não nasce do mero egoísmo, mas é desinteressada, e que é propriamente a maldade, a qual aumenta até a crueldade. Na crueldade, o sofrimento alheio não é mais meio para atingir os fins da própria vontade, mas fim em si mesmo (W I, p.422). 
Agora nos resta explanar sobre a única via moral para motivação dos nossos atos: a compaixão. Apesar de ser também desinteressada como na crueldade, aquele que é movido pela compaixão só age em função do bem alheio. $\mathrm{O}$ completo oposto. Nas ações movidas por esse sentimento, o fim das ações é aliviar o sofrimento da existência do outro. O sofrimento alheio toca de modo tão profundo o agente que ele sente aquela dor como se fosse a dele. Desse modo, já não existe mais uma distância entre mim e o outro. "Não há mais diferença egoística entre 'eu' e o 'outro', ocorre a identificação, os sofrimentos alheios são apreendidos como se fossem os seus"2. Segundo Schopenhauer, nela há uma sincera participação pelo bem-estar alheio e "nos sacrifícios desinteressados" (W I, p.436).

Nas ações motivadas pelo egoísmo, a Vontade é afirmada; nas ações motivadas pela compaixão, a Vontade é negada. O sentimento da compaixão é, portanto, uma negação da Vontade que, através dela, leva ao alcance da justiça e a caridade. Ainda que um nível inferior, ele nega o que lhe é próprio do sujeito egoísta e remove a barreira entre o "eu" e o sofredor. Nesse instante, o sofrimento é compartilhado e o ato da caridade é capaz de ser exercido. No entanto, findado o sofrimento do outro, não há mais lugar para a compaixão e tão logo o agente volta a agir egoisticamente como de costume porque, apesar do sentimento da compaixão mover o sujeito a negar a Vontade, as amarras egoístas ainda permanecem no corpo do agente. Isso acontece porque a negação da Vontade na ação motivada pela compaixão acontece num grau menos elevado. É necessário se desvincular completamente do corpo para atingir a verdadeira negação da Vontade.

O feliz e satisfeito como tal nos deixa indiferentes, justo porque seu estado é negativo: a ausência da dor, da falta e da necessidade. Podemos, por certo, contentarmo-nos com a felicidade, o bem-estar e o prazer de um outro, mas isto e secundário e mediado pelo fato de que, antes, seu sofrer e sua carência nos perturbam (E II, p.139).

Somente no ascetismo, este sim, a negação caminha para o seu grau máximo. O asceta é aquele que alcança um grau de conhecimento elevado e reconhece a essência trágica da vida, pois "toda vida é sofrimento" (W I, p. 360). Ele vê o mundo e nota que todos os nossos esforços são inúteis. Desse modo, esse indivíduo elevado sente um profundo sofrimento por toda vida humana. Ao sentir esse grau elevado de compaixão, o asceta transpassa o princípio de individuação e nega a sua própria natureza aceitando o sofrimento e renunciando aos prazeres do corpo.

Se aquele véu de maya, o principium individuationis, é de tal maneira removido dos olhos de um ser humano que este não faz mais diferença egoística entre a sua pessoa e a de outrem, no entanto compartilha em tal intensidade dos sofrimentos alheios como se fossem os seus próprios e assim é não apenas benevolente no mais elevado grau, mas está até mesmo pronto a sacrificar o próprio indivíduo tão logo muitos outros precisem ser salvos; então, daí, segue-se automaticamente que esse ser humano reconhece em todos os seres o próprio íntimo, o seu verdadeiro si mesmo e desse modo tem de considerar também os sofrimentos infindos de todos os viventes como se fossem seus: assim, toma para si as dores de todo o mundo; nenhum sofrimento é-lhe estranho (W I, p.439).

O asceta, voluntariamente, adota a castidade, a pobreza, aceita o sofrimento com uma paciência inesgotável e, por fim, atinge a completa negação da Vontade ao aceitar a

${ }^{2}$ DACOL, M. A compaixão como fundamento da moral em Schopenhauer, p. 54. 
morte através da mortificação do corpo. Ao constantemente negar as vontades do corpo como alimentar-se, por exemplo, a morte chega como uma espécie de redenção.

Então vemos o ser humano, trazido às raias do desespero após haver sofrido todos os graus de uma aflição crescente sob os reveses mais violentos, subitamente retirar-se em si mesmo, reconhecer a si mesmo e ao mundo, mudar todo o seu ser, elevar-se por sobre a própria pessoa e por todo sofrimento, como se fora purificado e santificado por este, em paz inabalável, em beatitude e sublimidade, livremente renunciando a tudo o que antes queria com a maior veemência, e receber alegremente a morte. Eis aí a mirada argêntea que subitamente surge da flama purificadora do sofrimento; a mirada da negação da Vontade. Ou seja, da redenção (W I, p. 455).

Mas e o suicídio? Schopenhauer afirma que se trata de "uma ação inútil e tola" (W I, p. 462). O homem que tira a sua própria vida quer a vida mais do que qualquer outro, mas quer tanto viver que não aceita qualquer vida.

Contrariamente, a pessoa que está oprimida pelo peso da vida e ainda assim a deseja e afirma, porém sem aceitar os tormentos dela, em especial sem poder suportar por muito tempo a dura sorte que lhe coube, não pode esperar da morte a libertação, nem pode salvar a si mesma pelo suicídio; é apenas seduzida com ilusões falsas pelo frio e tenebroso Orco, que se apresenta como um porto de paz (W I, p. 324 - 325).

Diante dos obstáculos que o impedem de alcançar o objeto desejado, num ato de intensa afirmação da Vontade, tira a própria vida. Parece contraditório, mas o que o suicida quer é viver. Mas, segundo Schopenhauer, "porque o suicida não cessa de querer, cessa de viver” (W I, p. 463). A condenação do filósofo acerca do suicídio está sustentada no plano metafísico. Aquele que comete suicídio está afirmando a Vontade, que é a vontade do corpo e, portanto, uma ação com motivações egoístas.

O suicídio alcançado pelo fenômeno da ascese se difere justamente por o contrário do suicida que não cessa de querer. $O$ asceta mortifica seu corpo constantemente numa paciência inesgotável. A objetificação da Vontade ocorre através do corpo, não consegue ser afirmada nos constantes jejuns, no autoflagelo e na abstinência sexual. "Trata-se da morte livremente escolhida por inanição, resultado do mais elevado grau de ascese(...). Tal tipo de suicídio provém simplesmente de o asceta, já por inteiro resignado, cessar de viver, simplesmente porque cessou por inteiro de querer" (W I, p. 464).

\section{O auto-sacrifício da enfermeira}

Observamos, em momentos de crises humanitárias como a que estamos vivendo, diversas ações imorais motivadas pelo instinto de sobrevivência ou qualquer outro tipo de motivação egoísta serem mais evidenciadas. Acompanhamos, por exemplo, um caso nos EUA onde um cidadão comprou uma quantidade absurda de material para proteção e higienização quando iniciou a epidemia do coronavírus no país. Com isso, segundo o The New York Times 3 , esses materiais faltaram nas prateleiras dos mercados locais e, aproveitando dessa situação, pôs à venda na internet a valores abusivos.

\footnotetext{
${ }^{3}$ NICAS, Jack. He has 17,70o bottles of hand sanitizer and nowhere to sell them. The New York Times, Nova Iorque, 15 de mar. de 2020. Disponível em: < https://www.nytimes.com/2020/03/14/technology/coronaviruspurell-wipes-amazon-sellers.html> Acesso em: 15 abr. 2020
} 
Outro caso foi de um empresário, mesmo sabendo que seu exame havia dado positivo para a covid-19, pegou seu jatinho e viajou para festejar na praia com os amigos regada a muita bebida. Ignorou as recomendações de quarentena e se aglomerou a outras pessoas. Ao ser questionado pelo seu ato negligente, segundo o jornal Pragmatismo Político ${ }^{4}$, o homem debochou: "o que um banho de mar não resolve?". Aqui nos deparamos com um ato natural do homem schopenhaueriano. "Estou doente, mas tenho uma festa para ir." Mesmo que este ato cause o mal de várias outras pessoas sadias como os convidados amigos dele e funcionários, o próprio piloto ou quem esteve com o empresário no jatinho dele. Essas pessoas foram meio para um único fim: a satisfação do corpo do agente. Aqui nos recordamos e podemos até sermos convencidos de que, como Schopenhauer disse, a satisfação do corpo vem sempre em primeiro lugar.

No entanto, não é só de exemplos como estes de ações egoístas que temos ciências nessa pandemia. Em Bergamo, na Itália, o padre Giuseppe Berardelli morreu ao ceder seu respirador para um jovem. Ambos estavam com a covid-19, mas ele preferiu ceder o aparelho que poderia salvar a sua vida, para alguém mais jovem e que, na teoria, teria mais tempo de vida pela frente do que ele que já tinha os seus 72 anos. 5

Fatos como esse se somam ao curioso caso da enfermeira italiana que escolheu tirar a sua própria vida para evitar que outras pessoas também fossem contaminadas. Cabe a nós indagarmos sobre a seguinte questão: O suicídio de Daniela Trezzi, este auto-sacrifício, seria uma afirmação da Vontade dentro do pensamento schopenhaueriano? Não seria este um caso concreto de uma ação motivada pela compaixão e, por tanto, uma negação da Vontade? A existência de ações com motivações altruístas é real. O filósofo nos confirma que a ação motivada pelo sentimento da compaixão "não é um processo sonhado ou apanhado no ar, mas algo bem real" (E II, p. 136).

Segundo a Federação Nacional de Enfermagem da Itália ${ }^{6}$, em nota, este não foi o primeiro caso desde a chegada do SARS-CoV-2 no território italiano. É mencionado, ainda na nota, mas sem muitos detalhes, um caso igual a este de uma outra profissional da saúde na cidade de Veneza ocorrido uma semana antes. Apesar de não ser detalhado como o caso de Daniela, tomamos conhecimento que não se trata de um evento isolado. $\mathrm{O}$ auto-sacrifício existe e acontece, mesmo que de forma muitas vezes anônima em nosso dia a dia. Chamamos aqui este suicídio de auto-sacrifício porque neste ato de sacrifício é a própria vida que é dada por alguém e por um motivo: a compaixão.

É verdade que é um acontecimento bastante trágico, mas quem não a julgaria como uma espécie de heroína por esta escolha, ainda que fúnebre? Alguém que age no máximo do altruísmo ao ponto de tirar a própria vida para que pessoas, estranhas a ela ou não, possam ter menos chances de contrair este coronavírus. Existe alguém que negue o valor moral desse ato soturno? Ela, que viu de perto tantas pessoas morrerem, ao se ver contaminada, muito provavelmente, lembrou de todo sofrimento que presenciou em seus pacientes enquanto atuava no hospital. Ela certamente, ao decidir se auto sacrificar, decidiu um

\footnotetext{
${ }^{4}$ Empresário que fugiu de isolamento espalhou coronavírus em Trancoso-BA. Pragmatismo Político, 17 de mar. de 2020. Disponível em: < https://www.pragmatismopolitico.com.br/2020/o3/empresario-que-fugiu-deisolamento-espalhou-coronavirus-em-trancoso-ba.html?fbclid=IwARolQMbefGytV-9dINiI-

Kd_KxTQoy6e_a8TpI6-GbaiusHiiYjCBTVpirk> Acesso em: 15 abr.2020

5 LELLES, Coronavírus: Morre na Itália padre que cedeu respirador para paciente mais jovem. Estado de Minas, 24 de mar. de 2020. Disponível em: <

https://www.em.com.br/app/noticia/internacional/2020/03/24/interna_internacional,1132001

${ }^{6}$ Federazione Nazionale Ordini Professioni Infermieristiche. Al fronte di COVID-19 non si muore solo per il vírus., Roma, 24 de mar. de 2020. Disponível em: < https://www.fnopi.it/2020/03/24/san-gerardo-infermierasuicida/> Acesso em: 15 abr. 2020
} 
dilema: viver esperando se recuperar e assumir a responsabilidade de contaminar outras pessoas ou dar fim a sua vida e, assim, não ser possível contaminar ninguém.

Se nos livrarmos de todos os tabus religiosos em cima da morte voluntária, o que sobra do suicídio de Daniela senão um ato de compaixão? O suicídio asceta, admirado por Schopenhauer, é processual. O sujeito passa por um processo de graduais negações da Vontade ao se abster sexualmente, ao jejuar, ao autoflagelar-se numa paciência infinita até a morte por inanição. $\mathrm{O}$ asceta já aceitou o sofrimento. Ele teve o conhecimento da existência miserável e trágica da humanidade. No entanto, a negação da Vontade no auto-sacrifício ocorre num único instante. A morte no asceta vem como uma redenção igualmente àquele quem comete o auto-sacrifício. O nosso filósofo reconhece a dificuldade de explicar o que seria intermediário entre a o suicídio através da acesse e daquela, que ele chama de comum, através do desespero. Segundo Schopenhauer, "deve haver muitos graus intermédios e combinações que são certamente difíceis de explicar; mas a mente humana tem profundezas, obscuridades e complicações que são extremamente difíceis de aclarar e destrinchar" (W I, p.466). Não é fácil realmente tentar explicar ou compreender aquele que age no grau máximo de altruísmo e da caridade. No auto-sacrifício o alvo é sempre livrar o outro do sofrimento presente ou futuro a custo da própria vida.

Entende-se melhor a escolha feita por Daniela quando resgatamos os relatos que eram sobre o medo que ela tinha de contaminar outras pessoas. A sua morte seria uma forma de diminuir a dor de diversas famílias. E aqui nos recordamos de uma observação muito importante deixada por Schopenhauer que faz todo o sentido no caso Daniela Trezzi: os aplausos da consciência.

Acrescente-se, como uma característica bem íntima e não tão evidente das ações dotadas de valor moral, o fato de que elas deixam ficar um certo contentamento com nós mesmos que é chamado de aplauso da consciência (...). Além disso, como marca externa e acidental, tem-se a de que as ações do primeiro tipo ocasionam o aplauso e o respeito das testemunhas que não participam delas, e as do segundo tipo, o contrário (W I, p. 131).

Poderia alguém afirmar que Daniela estivesse então pensando em algum tipo de satisfação egocêntrica ao cometer o auto-sacrifício? Para essa questão, Schopenhauer responderia que, pensar desta forma, seria um "truque ilícito" (W I, p. 129) e que "são muito poucos os que duvidam disso e não tem a convicção, a partir da própria experiência, de que, muitas vezes, as pessoas se comportam de modo justo única e exclusivamente a fim de que não ocorra com os demais qualquer injustiça” (W I, p. 129). Este suicídio possui uma motivação caridosa de um genuíno amor para com o outro.

Se forem puras de todos os motivos egoístas e, por isso mesmo, se despertarem em nós aquele contentamento íntimo que chamamos de consciência boa, pacificadora e aprovadora. Tal participação deve também provocar no observar a aprovação, o respeito, a admiração e, até mesmo, um olhar de humilhação em relação a si próprio, fato que não pode ser negado (E II, p. 160).

Quantos de nós daríamos a própria vida pelo outro? Novamente: Quem não a julgaria como uma espécie de heroína? O auto-sacrifício de Daniela nos emociona, não somente pela atitude extrema e trágica que é alguém tirar a própria vida, mas sim por nos causar essa humilhação em relação a nós mesmos. Trata-se de um ato próprio da negação da Vontade. Tentar compreender este fenômeno é impossível, pois aqui não cabe espaço a razão. 
Segundo Schopenhauer, "Este processo é misterioso, pois é algo de que a razão não pode dar conta diretamente" (E II, p. 163).

\section{Referências}

DALCOL, Mônica Saldanha. A compaixão como fundamento da moral em Schopenhauer. 2014. 88 f. Dissertação (Mestrado em Filosofia) - Universidade Federal de Santa Maria, Santa Maria, 2014.

SCHOPENHAUER, Arthur. O mundo como vontade e como representação. (W I). Tomo I; tradução, apresentação, notas e índices de Jair Barboza. - 2.ed. - São Paulo: Editora UNESP, 2015

SCHOPENHAUER, Arthur. Sobre o fundamento da moral. Trad. Maria Lùcia Mello Oliveira Cacciola. São Paulo: Martins Fontes, 2001.

Federazione Nazionale Ordini Professioni Infermieristiche. Al fronte di COVID-19 non si muore solo per il vírus., Roma, 24 de mar. de 2020. Disponível em: < https://www.fnopi.it/2020/03/24/san-gerardo-infermiera-suicida/> Acesso em: 15 abr. 2020

NICAS, Jack. He has 17,70o bottles of hand sanitizer and nowhere to sell them. The New York Times, Nova Iorque, 15 de mar. de 2020. Disponível em: < https://www.nytimes.com/2020/o3/14/technology/coronavirus-purell-wipes-amazonsellers.html> Acesso em: 15 abr. 2020

Enfermeira comete suicídio na Itália após receber diagnóstico de coronavírus. Folha de $\mathbf{S}$. Paulo, São Paulo, 26 de mar. de 2020. Disponível em: <https://www1.folha.uol.com.br/mundo/2020/o3/enfermeira-comete-suicidio-na-italiaapos-receber-diagnostico-de-coronavirus.shtml. Acesso em: 15 abr.2020

DIAS, Roger. Enfermeira italiana se suicida depois de contrair coronavírus. Estado de Minas, 25 mar. de de 2020. Disponível em: < https://www.em.com.br/app/noticia/internacional/2020/03/25/interna_internacional,113250 4/enfermeira-italiana-se-suicida-depois-de-contrair-coronavirus.shtml>. Acesso em: 15 abr.2020

Empresário que fugiu de isolamento espalhou coronavírus em Trancoso-BA. Pragmatismo Político, 17 de mar. de 2020. Disponível em: < https://www.pragmatismopolitico.com.br/2020/o3/empresario-que-fugiu-de-isolamentoespalhou-coronavirus-em-trancoso-ba.html?fbclid=IwARolQMbefGytV-gdINiIKd_KxTQoy6e_a8TpI6-GbaiusHiiYjCBTVpirk> Acesso em: 15 abr.2020

LELLES, Ana Raquel. Coronavírus: Morre na Itália padre que cedeu respirador para paciente mais jovem. Estado de Minas, 24 de mar. de 2020. Disponível em: < https://www.em.com.br/app/noticia/internacional/2020/03/24/interna_internacional,113200 1/coronavirus-morre-na-italia-padre-que-cedeu-respirador-para-paciente.shtml> Acesso em: $15 \mathrm{abr} .2020$ 